\title{
Alpine tundra species phenology is mostly driven by climate-related variables rather than by photoperiod
}

\author{
QUAGLIA Elena1* iD https://orcid.org/oooo-0oo1-9087-3152; ${ }^{\wedge}$ e-mail: elena.quaglia@unito.it

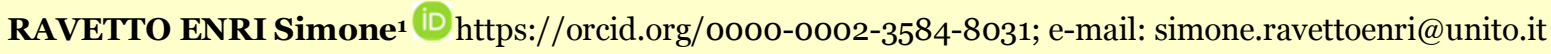 \\ PEROTTI Elisa² (D) https://orcid.org/oooo-0oo2-6277-4410; e-mail: elisa.perotti@agroscope.admin.ch
}

PROBO Massimiliano² (D https://orcid.org/oooo-0002-0017-7557; e-mail: massimiliano.probo@agroscope.admin.ch

LOMBARDI Giampiero1† (iD https://orcid.org/oooo-0oo3-3787-2374; e-mail: giampiero.lombardi@unito.it

LONATI Michele1† (iD https://orcid.org/oooo-0oo1-8886-0328; e-mail: michele.lonati@unito.it

\author{
* Corresponding author \\ † These authors contributed equally to this work. \\ 1 Department of Agricultural, Forest and Food Sciences, University of Torino, Largo Paolo Braccini 2, 10o95, Grugliasco (To), \\ Italy \\ 2 Grazing Systems, Agroscope, Route de Duillier 5o, 1260, Nyon, Switzerland
}

Citation: Quaglia E, Ravetto Enri S, Perotti E, et al. (2020) Alpine tundra species phenology is mostly driven by climaterelated variables rather than by photoperiod. Journal of Mountain Science 17(9). https://doi.org/ 10.1007/s11629-020-6079-2

(C) The Author(s) 2020.

\begin{abstract}
The study of plant phenology has frequently been used to link phenological events to various factors, such as temperature or photoperiod. In the high-alpine environment, proper timing of the phenological cycle has always been crucial to overcome harsh conditions and potential extreme events (i.e. spring frosts) but little is known about the response dynamics of the vegetation, which could shape the alpine landscape in a future of changing climate. Alpine tundra vegetation is composed by an array of species belonging to different phytosociological optima and with various survival strategies, and snowbed communities are a relevant expression of such an extreme-climate adapted flora. We set eight permanent plots with each one in a snowbed located on the Cimalegna plateau in Northwestern Italy and then we selected 10 most recurring species among our plots, all typical of the alpine tundra environment and classified in 3
\end{abstract}

Received: 12-Mar-2020

$1^{\text {st }}$ Revision: 11-Jun-2020

$2^{\text {nd }}$ Revision: 30-Jun-2020

Accepted: 16-Jul-2020 different pools: snowbed specialists, grassland species and rocky debris species. For 3 years we registered the phenophases of each species during the whole growing season using an adaptation of the $\mathrm{BBCH}$ scale. We later focused on the three most biologically relevant phenophases, i.e., flower buds visible, full flowering, and beginning of seed dispersion. Three important season-related variables were chosen to investigate their relationship with the phenological cycle of the studied species: (i) the Day Of Year (DOY), the progressive number of days starting from the $1^{\text {st }}$ of January, used as a proxy of photoperiod, (ii) Days From Snow Melt (DFSM), selected to include the relevance of the snow dynamics, and (iii) Growing Degree Days (GDD), computed as a thermal sum. Our analysis highlighted that phenological development correlated better with DFSM and GDD than with DOY. Indeed, models showed that DOY was always a worse predictor since it failed to overcome interannual variations, while DFSM and marginally GDD were better suited to predict the phenological development of most of the species, despite differences in 
temperature and snowmelt date among the three years. Even if the response pattern to the three variables was mainly consistent for all the species, the timing of their phenological response was different. Indeed, species such as Salix herbacea and Ranunculus glacialis were always earlier in the achievement of the phenophases, while Agrostis rupestris and Euphrasia minima developed later and the remaining species showed an intermediate behavior. However, we did not detect significant differences among the three functional pools of species.

Keywords: Alpine plants; Climate change; Growing degree days; Italian Alps; Salix herbacea; Snowbed vegetation

\section{Introduction}

The most recent scenarios show that highelevation and high-latitude biomes have been remarkably affected by Climate Change and the impacts will rapidly increase in the next future (IPCC 2019b). Therefore, the European Alpine region will likely witness an increasingly dramatic warming and a severe alteration of snow dynamics (Rixen et al. 2008). In this biogeographic region, the so-called 'snowbeds' are landscape portions generally located at altitudes above $2500 \mathrm{~m}$ a.s.l. on small, flat surfaces, where snow cover lasts up to 10 months/year on relatively deep soils with considerable organic layers (Freppaz et al. 2010). During the snow cover period, thanks to the insulating properties of the thick snowpack, soil temperature seldom drops below $\mathrm{O}^{\circ} \mathrm{C}$ and freezethaw cycles are rare (Carbognani et al. 2012; Petraglia et al. 2014). Although currently fragmented, snowbeds may help detecting which climatic alterations could potentially threaten the whole arctic and alpine biomes in the future (Björk and Molau 2007). According to the most recent reports, snow-dependent species of polar and mountain regions are already declining in abundance and their seasonal activities suffer from alterations due to changes in winter and spring climatic dynamics, causing an increase in their risk of extinction (IPCC 2019b). Even species that are not threatened in the short term, due to a higher ecological plasticity, are likely to suffer a decrease in their overall performances (Sedlacek et al. 2015).
The snowbed vegetation is composed by a specific array of species, comprising a number of different survival strategies. Indeed, within this habitat, species with different phytosociological optima can coexist, and three main functional pools of species can be generally found, namely (a) snowbed species, (b) grassland species and (c) debris species. Also Ninot et al. (2013), studying functional traits of alpine tundra plants, grouped species into these three categories. More specifically, together with snowbed specialists, which are the most adapted to the long-lasting snow cover conditions, typical grassland species as well as ridge and pioneer species from surrounding grasslands and rocky outcrops can profit of small scale niche differentiation within the snowbed (Körner 2003). Unlike the ridge vegetation which is adapted to resist severe cold, strong winds and spring frost, snowbed vegetation benefits from the insulation provided by the thick, long-lasting snowpack. The persistence of this layer not only prevents possible late spring frost damages on plants reproductive structures, but it also maintains an ideal soil moisture content during the whole growing season (Isard 1986). Within this habitat, most of the species are perennials, for instance, the most distinctive snowbed species is the dwarf shrub Salix herbacea L., which despite the small size of the aerial parts can develop an impressive and extremely ramified root system and shows pronounced longevity (Wijk 1986; Beerling 1998). Some other species, such as Poa alpina L. subsp. vivipara, implement a strategy of agamic reproduction instead of the gamic one, which at this elevation requires a higher energetic effort and has a lower success rate.

Phenology has been frequently used to investigate the response of the life cycle of alpine plants to a wide range of environmental and climatic variables (Ernakovich et al. 2014; Khorsand et al. 2015; Ding et al. 2016). Additionally, phenology is an effective parameter to test whether or not species will be able to adapt with the progressive anticipation of snowmelt (Schmid et al. 2017), since the correct timing of sensitive phenophases is crucial for their survival. Indeed, in the alpine environment, rising temperatures and sudden alterations in the snow dynamics, such as reductions in mass and duration of the snow layer, are the most likely drivers of 
changes that could affect plant species survival (Huelber et al. 2006). The high-elevation environment is likely to maintain, in the short term, a certain degree of protection against spring frost, due to a less dramatic reduction of the amount and duration of the snow cover (Klein et al. 2018) when compared to low or medium-elevation environments, which are more at risk of frostrelated damage (Vitasse et al. 2018). On the other hand, more competitive species of typical alpine grasslands could benefit from advantages such as the elongation of the growing season (Wang et al. 2016) or the increased nutrient input in the soil due to a higher bacterial activity (Freppaz et al. 2008) at the expense of the strongly adapted snowbed specialists. Most of the literature carried out up to now has mainly focused on the flowering phenological stages (Totland et al. 2002; Kawai and Kudo 2011; Carbognani et al. 2016; Richardson et al. 2017), while the analyses of other phenophases which could be relevant for the success of the species is far less common.

In our study, we assessed the linkages between plant phenology (expressed through phenophases) and three temporal and climate-related explanatory variables that are commonly used in literature to predict the progression of phenological events. The first one was the Day Of Year (DOY), the Julian date or progressive number of days starting from the $1^{\text {st }}$ of January, as it is widely considered to be an effective proxy of the photoperiod for alpine vegetation (Kimball et al. 2014) and has been frequently adopted to describe flowering phenophase, especially at low-elevation environments (for instance by Moriondo et al. 2001 and Iannucci et al. 2008). A conspicuous number of studies have also explored its suitability to outline the response of alpine plant communities to photoperiod (Kimball et al. 2014; Petraglia et al. 2014). Snowbed vegetation is generally expected to be less responsive to this factor when compared to communities typical of early melting snow cover sites (Hülber et al. 2011) but, due to its composite pool of species and the interaction of multiple environmental factors, the correlation between snowbed species phenology and DOY is still far from being thoroughly inspected. The second variable we used was Days From Snow Melt (DFSM), which is the progressive number of days after snowmelt (used in Wang et al. 2015; Delnevo et al. 2018). It represents a simple yet effective explanatory variable to explore the relationship between plant phenology and the spring dynamics of the snowpack (Kimball et al. 2014; Petraglia et al. 2014) and to understand the relationships between the risk of late frost damage and an increasingly early snowmelt. In snow-dependent habitats this kind of variables are widely adopted to investigate the risk of frost damage correlated to an increasingly early snowmelt, but its use to describe the whole phenological cycle has been less frequent. The third explored variable was Growing Degree Days (GDD), which accounts for the sum of temperatures above which plants carry out their physiologic processes starting from a certain baseline temperature. GDD is largely adopted in agronomy and plant science and considered an effective predictor of plant phenological responses (Moriondo et al. 2001; Lonati et al. 2009; Sedlacek et al. 2015). Nevertheless, it is still uncertain to what extent thermal requirements of alpine species are due to their plasticity or their genetic adaptation (Kawai and Kudo 2011; Domenech et al. 2016).

The aim of the present study was to investigate the occurrence of certain phenophases in a pool of alpine tundra species belonging to different functional groups (i.e. snowbed, grassland and debris species), taking into account interannual fluctuations. The objective of this research was to address the following questions: 1 . Which temporal and climate-related variable is more related to the phenophases of different alpine tundra species? 2. Are there significant differences in the phenological development among these species? 3. Are there any differences among functional pools of species?

\section{Materials and Methods}

\subsection{Study area}

The experiment was carried out at the Cimalegna Plateau (Sesia Valley, North-western Italian Alps), an area close to Monte Rosa Massif $\left(45^{\circ} 52^{\prime} 12.0^{\prime \prime N}, 7^{\circ} 53^{\prime} 3.0^{\prime \prime E}\right)$ and with an elevation ranging between 2600 and $2900 \mathrm{~m}$ a.s.l. The whole area is included in the international Long Term Ecological Research monitoring network (LTER 2020), within the site Mosso, Passo Salati-Col 
d'Olen (IT).

The bedrock was mainly micaschists, with some inclusions of ophiolites and calcicschists (Magnani et al.). Within the Plateau, the vegetation was composed by a mosaic of three main phytosociological associations: (i) Androsacetum alpinae (Br.Bl. in Br.Bl. et Jenny 1926) on the steeper slopes with medium or large silicic debris; (ii) Caricetum curvulae (Rübel 1911) with acidic grasslands species on windy ridges and gentle slopes; and (iii) Salicetum herbaceae (Rübel 1911) on snowbeds with longer snow cover duration and deeper soils.

During the last decade the area was characterized by a mean annual air temperature of $7^{\circ} \mathrm{C}$ in the snow-free period, a cumulative average annual snowfall of $805 \mathrm{~cm}$, and a mean annual liquid precipitation of $283 \mathrm{~mm}$ (Meteomont, Stazione Mosso). The snow cover duration lasted 263 days on average, with the snowpack developing by late October - early November, while snowmelt starts in late May to early June on the steeper and more sunny slopes and up to mid-July in some of the shadiest snowbeds.

\subsection{Phenological monitoring}

A set of eight permanent plots was established within eight snowbed sites (Figure 1), all including the Salicetum herbaceae association. Plots were located at an altitude ranging from 2686 to $2854 \mathrm{~m}$ a.s.l., on flat and homogeneous surfaces.

Each plot was a $4 \mathrm{~m} \times 4 \mathrm{~m}$ square and was equipped at ground level with a HOBO Pro v2 U23oox (Onset Corp., Pocasset, MA) thermal probe measuring hourly temperature since the beginning of the monitoring.

During the summer 2015, botanical surveys were carried out to describe the plot vegetation composition and identify the most frequent plant species. For the phenological monitoring we selected ten species which were widespread over the Plateau and common among the eight plots (Table 1). In this study, we grouped the species in three functional species pools that reflect the main habitats in the surroundings. In order to identify the different pools, which were characterized by similar ecological needs, we classified each species according to its phytosociological optimum at the

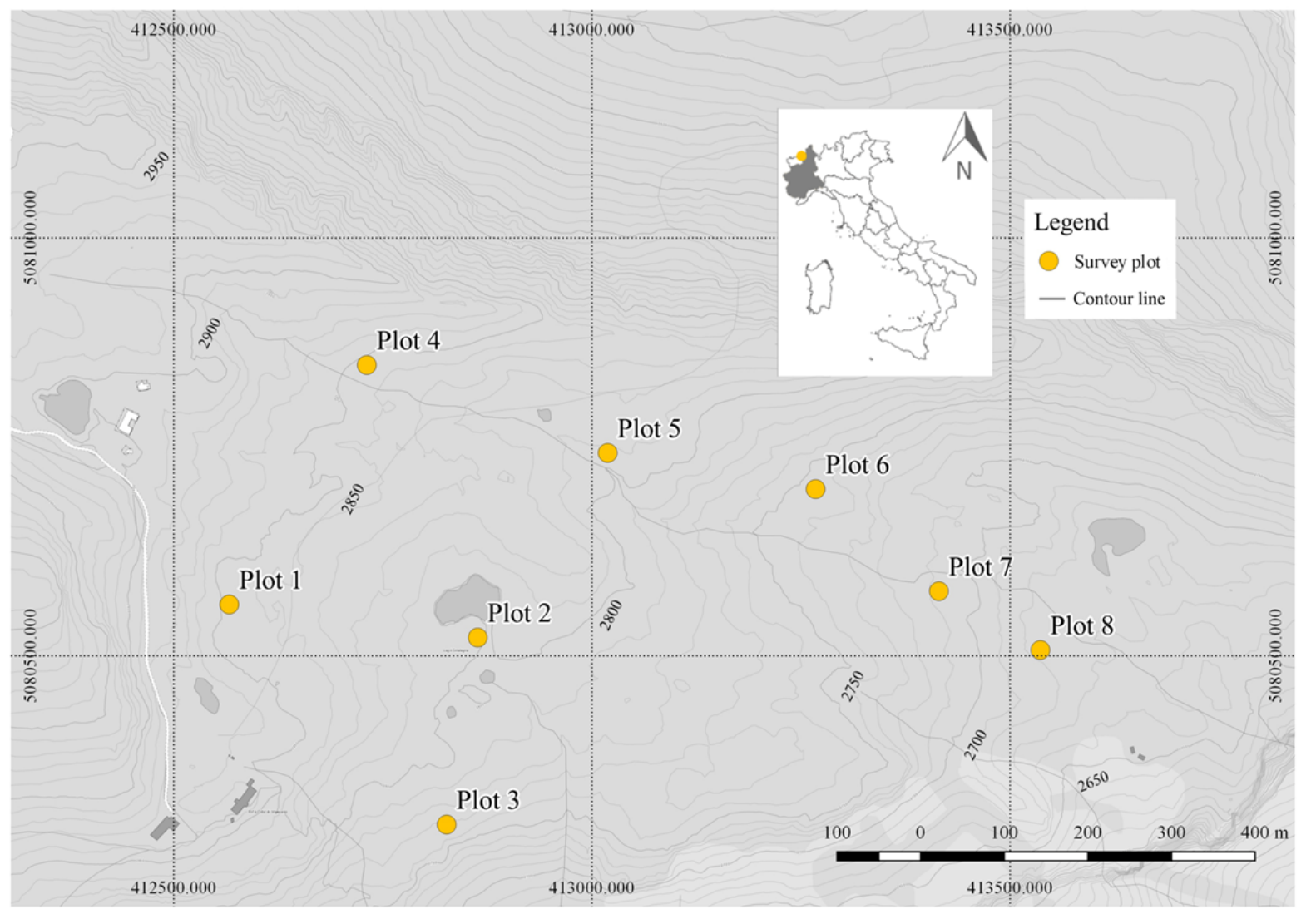

Figure 1 Distribution of the survey plots on the Cimalegna Plateau, in the Western Italian Alps. Coordinates are referred to the system WGS 84 /UTM zone $32 \mathrm{~N}$. 
Table 1 List of the target species selected for this study, with their growth form, optimum class and the identification of functional pool.

\begin{tabular}{l|l|l|l|} 
Species & Growth form & Optimum class & $\begin{array}{l}\text { Functional } \\
\text { species pool }\end{array}$ \\
\hline $\begin{array}{l}\text { Agrostis rupestris All. } \\
\text { Alchemilla pentaphyllaea L. }\end{array}$ & Perennial graminoid & Elyno-Seslerietea variae & Grassland \\
Euphrasia minima Jacq. ex DC. & Perennial forb & Salicetea herbaceae & Snowbed \\
Gnaphalium supinum L. & Perennial forb & Suncetea trifidi & Grassland \\
Leucanthemopsis alpina (L.) Heywood & Perennial forb & Juncetea trifidi & Snowbed \\
Luzula alpinopilosa (Chaix) Breistr. & Perennial graminoid & Salicetea herbaceae & Grassland \\
Poa alpina L. & Perennial graminoid & Molinio-arrenatheretea & Grassland \\
Ranumculus glacialis L. & Perennial forb & Thlaspietea rotundifolii & Debris \\
Salix herbacea L. & Perennial shrub & Salicetea herbaceae & Snowbed \\
Veronica alpina L. & Perennial forb & Thlaspietea rotundifolii & Debris
\end{tabular}

class level, following Aeschimann et al. (2004). Moreover, species in phytosociological classes having physiognomic, ecological, and floristic similarity were pooled according to Aeschimann et al. (2004). Accordingly, we were able to identify three main functional species pools: snowbed specialist species (hereafter, snowbed), typical alpine grassland species (hereafter, grassland) and rocky debris species (hereafter, debris).

For the phenological monitoring each $4 \mathrm{~m} \times 4$ $\mathrm{m}$ plot was permanently divided in 16 subplots $1 \mathrm{~m}$ $\times 1 \mathrm{~m}$ used as pseudo-replicates, where we recorded the phenophase of the most advanced individual of each species. The phenophase was assigned with a visual observation using an adaptation of the BBCH scale (Hack et al. 1992) fitted for the snowbed plant communities as a reference (Appendix 1). Such adapted scale consists in a series of progressive numbers ranging from 0 to 59, with the tens representing the major phenophases in chronological order (Shoots emergence, Leaves development, Flower buds, Flowering, Fruiting, Seed dispersal) and the units representing the advancement of said phenophases. The surveys were carried out every vegetative season along a three-year span (2016, 2017 and 2018) for seven up to nine times per year. Since the initial stages occurred very quickly right after snow melt, the monitoring dates were closer, thus the surveys were carried out every week at the beginning of the growing season (i.e. June-July). The frequency of the surveys was reduced to one monitoring date every two or three weeks towards its end (i.e. August-September), matching the deceleration of the growing cycle and the greater time lag occurring between recognizable phenophases. The average frequency at the beginning of the growing season was coherent with other studies in the Alpine area (Larl et al. 2006; Filippa et al. 2015; Carbognani et al. 2016). A photographic handbook of the phenophases was drawn during the first year of monitoring to avoid, as far as possible, interannual surveying bias. The subplots in which no individual for a given species reached at least the flowering stage at the end of the season were excluded from further analysis.

\subsection{Statistical analysis}

We considered the raw stages as pseudoreplicates, therefore we did not use them as replicates in the further statistical analyses. For every monitoring date, the phenophase of the species occurring in each plot was calculated as the median value of the 16 subplots, in order to avoid outliers. We studied the relationships between plant phenophases and DOY, DFSM, and GDD to investigate the effects of these three temporal and climate-related variables as proxies of photoperiod, snow dynamics and temperature, respectively. The values of the three proxy variables were interpolated on three phenophases selected as the most relevant for their biological role: (i) Phenophase 20, corresponding to inflorescence or flower buds visible; (ii) Phenophase 35, corresponding to full flowering; and (iii) Phenophase 50, corresponding to the beginning of seed dispersal. Since plants are sensitive to climatic threats, such as late spring frost, these phenophases were selected as the most relevant, since they are critical for plant survival and reproduction. The GDD base $0^{\circ} \mathrm{C}$ was calculated for every date and plot starting from the $1^{\text {st }}$ of January (Figure 2). This type of thermal sum was used instead of the more common GDD base $5^{\circ} \mathrm{C}$, since alpine plants have lower thermal requirements 


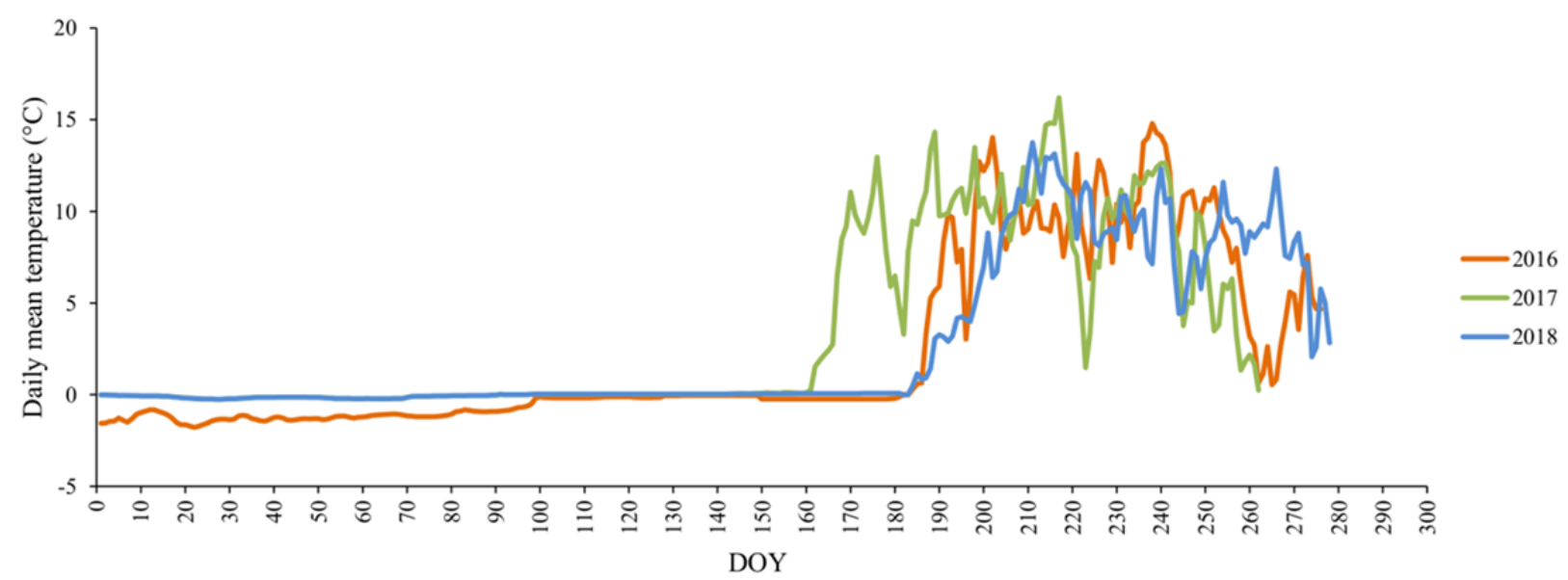

Figure 2 Daily mean temperatures $\left({ }^{\circ} \mathrm{C}\right)$ of all the plots starting from the $1^{\text {st }}$ of January, for the three studied years. Time is expressed as DOY, Day of Year.

when compared with lowland species (Legault and Cusa 2015; Carbognani et al. 2016; Mulder et al. 2017).

In order to explore the relationship between the phenological development and explanatory variables, a correlation analysis (Spearman's correlation) was carried out separately for each species. The medianphenophases values, recorded during all the years and in all the plots, were plotted per each species against DOY, DFSM and GDD separately. Spearman's coefficient was computed and used to compare the different correlations.

Then, in order to analyze the interannual differences we used Generalized Linear Mixed Models (GLMMs) for each species and for each phenophase. Separate models were run with DOY, DFSM and GDD set as response variables against year while the plot was used as random factor. We built models using both Gaussian and Gamma distribution, then we chose the best fitting one, i.e. that one showing the lowest Akaike Information Criterion (Zuur et al. 2009). When significant differences were found, Tukey's post-hoc tests were used to assess variations in vegetation response amongst years.

Finally, to compare how the phenological development of different species could respond to different factors, GLMMs were again run separately on the values interpolated on the three phenophases. Models were built with DOY, DFSM and GDD as target variables, species as a fixed factor while plot and year were considered as random factors. When significant effects were found Tukey's post-hoc test was used to assess differences amongst species. The same analysis was performed using functional pool of species as fixed factors, to compare difference between snowbed species, grassland species and species of the rocky debris. The DOY, DFSM and GDD were used as response variables against functional species pool, while species were set as fixed factors and plot and year random factor. We built models using both Gaussian and Gamma distribution, selecting the one with a lower AIC (Akaike Information Criterion) according to Zuur et al. (2009).

All the statistical analyses were performed with R 3.5.2.

\section{Results}

\subsection{Interannual differences}

The temperature trends of the three studied years within the eight monitored plots are reported in Figure 1. Over the course of the monitoring, average yearly temperatures of whole snow-free period had small differences $\left(8.5^{\circ} \mathrm{C}\right.$ in $2016,8.6^{\circ} \mathrm{C}$ in 2017 and $7.9^{\circ} \mathrm{C}$ in 2018). On the other hand, both the length of the snow-free season and the date of snowmelt varied among years, highlighting how 2017 was different from years 2016 and 2018. The snowmelt date for all the eight plots was on average on DOY 187 during year 2016, on DOY 165 during 2017 and on DOY 194 during 2018, i.e. with a variation range of about a month. The average variation in snowmelt date among plots was 17 days throughout the whole monitoring period, with a difference of respectively 11 and 14 days between 
the earliest and latest melting plot during years 2016 and 2018, while a difference of 25 days was assessed during year 2017. The interannual trend of snowmelt date (represented by the first spike after the flat line in Figure 1) was consistent throughout all the plots.

All the correlations between plant species phenophases and DOY, DFSM and GDD were significant with high $\mathrm{R}$ values (Figures 3, 4 and 5). The value of the comparison of Spearman's coefficients highlighted that correlation between plant phenophases and DOY was always lower than correlations between phenophases and DFSM and GDD, this trend being consistent throughout all the species and functional pools. Correlation coefficients of DFSM and GDD were considerably similar, with the first being slightly higher than the latter for eight out of ten species. The only exceptions were $P$. alpina and $A$. rupestris where the two values were equal.
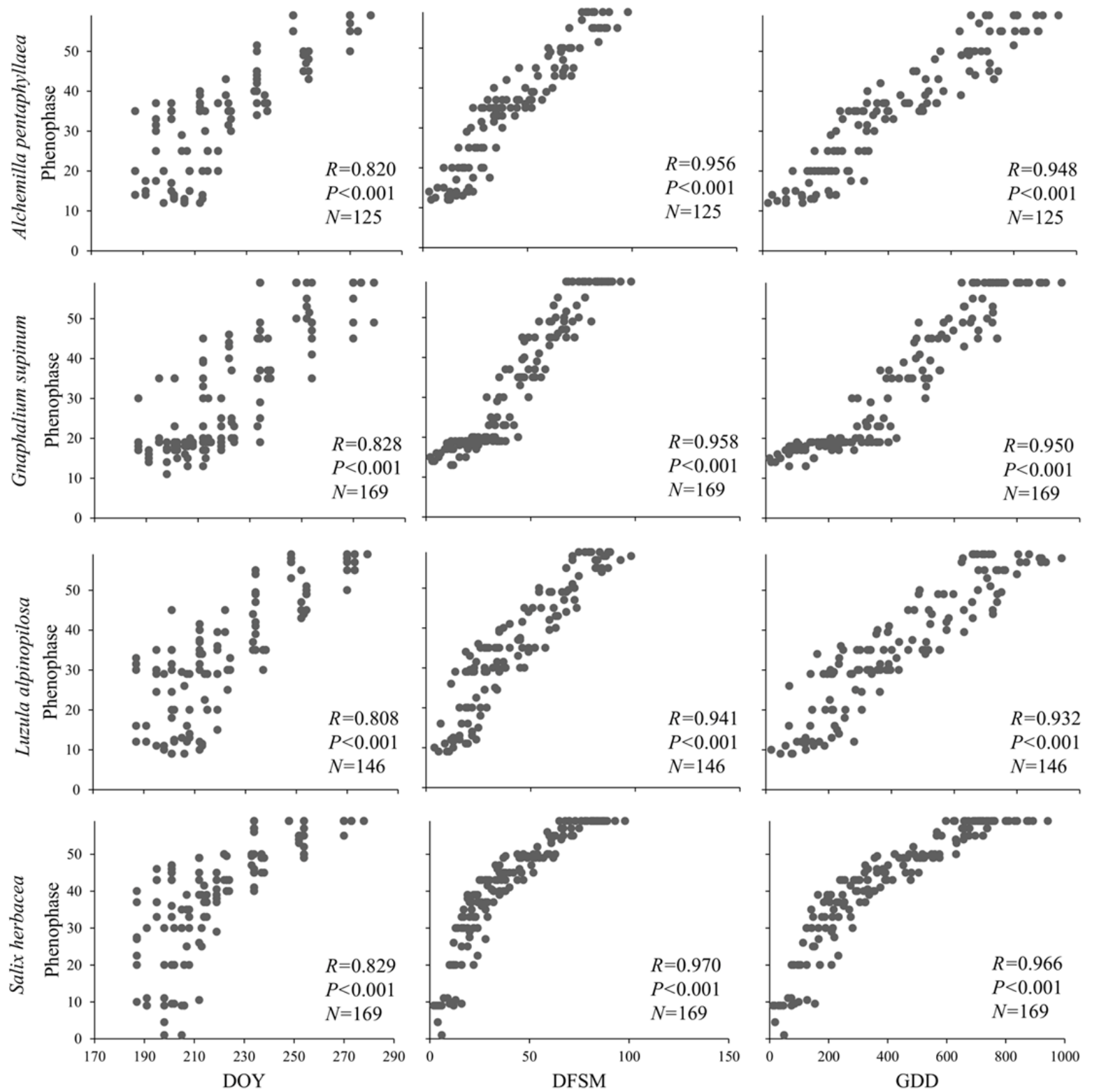

Figure 3 Correlations between phenophases of the snowbed species and Day Of Year (DOY), Days From Snow Melt (DFSM) and Growing Degree Days (GDD). Every point represents the median phenophase of the 16 subplots at a defined survey date in a single plot and year. Plant phenophases are expressed as a progressive number following the adaptation of BBCH scale (Hack et al. 1992). Spearman's $r$ and significance of the correlation are indicated in every chart. 

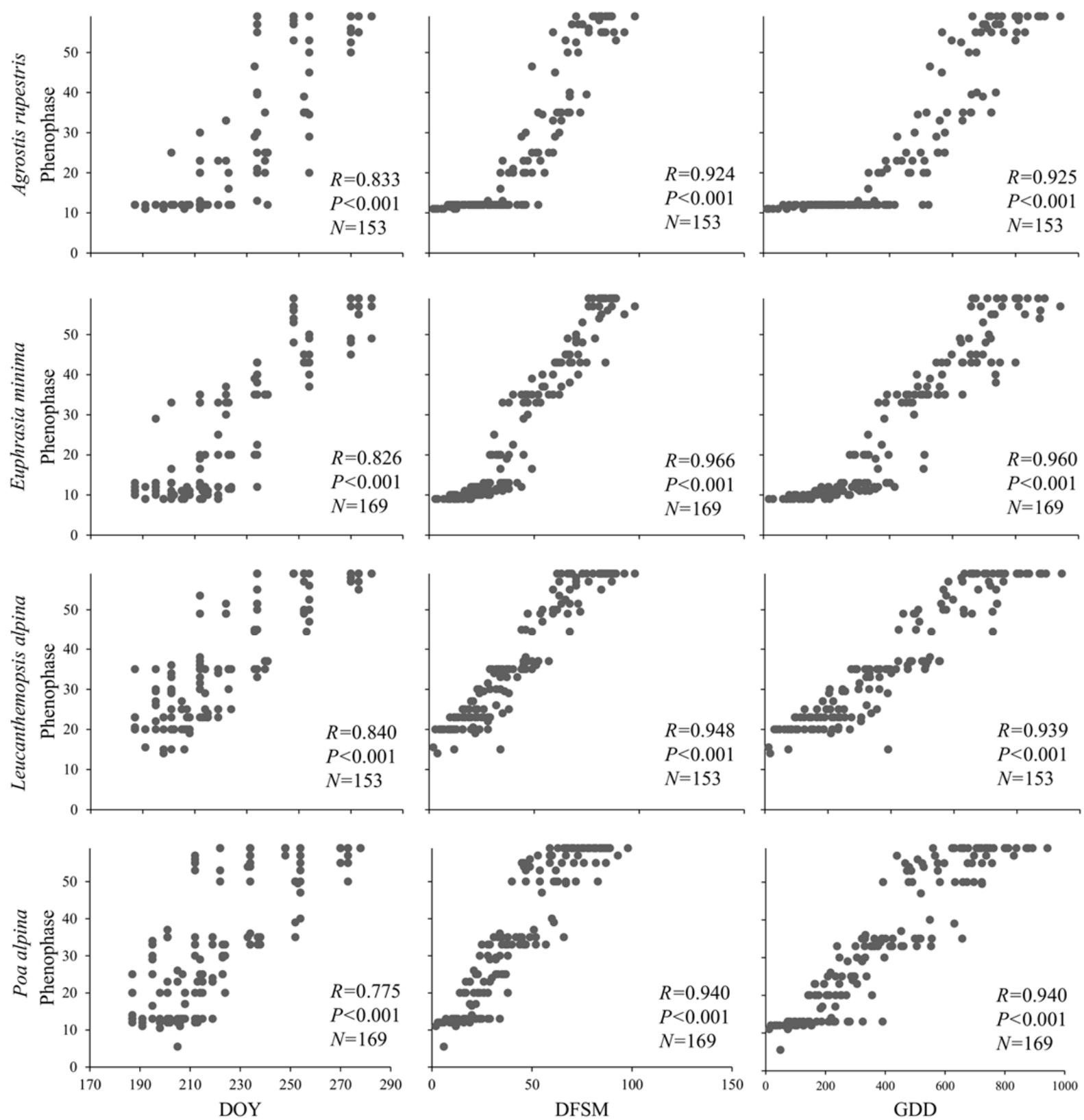

Figure 4 Correlations between phenophases of the grassland species and Day Of Year (DOY), Days From Snow Melt (DFSM) and Growing Degree Days (GDD). Every point represents the median phenophase of the 16 subplots at a defined survey date in a single plot and year. Plant phenophases are expressed as a progressive number following the adaptation of BBCH scale (Hack et al. 1992). Spearman's $r$ and significance of the correlation are indicated in every chart.

For all the species and phenophases, DOY values were the most unstable, with significant differences among years recurring in all the cases (Table 2). Moreover, while considering the DOY values of different species and phenophases, $80 \%$ of the cases showed exactly the same trend along the growing season. The DOY values for 2016 and 2018 were always grouped in the same post-hoc group and set apart from year 2017, which showed lower values. Not significant difference among years was detected in $56 \%$ of the cases for the DFSM models and $33 \%$ of the cases for GDD models. The results were not consistent throughout all the species and phenophases. For some species the response to the variables was mutually exclusive ( $R$. glacialis and $A$. rupestris were responsive to DFSM only, not to GDD) while for L. alpinopilosa and L. alpina the responses to both variables were perfectly 

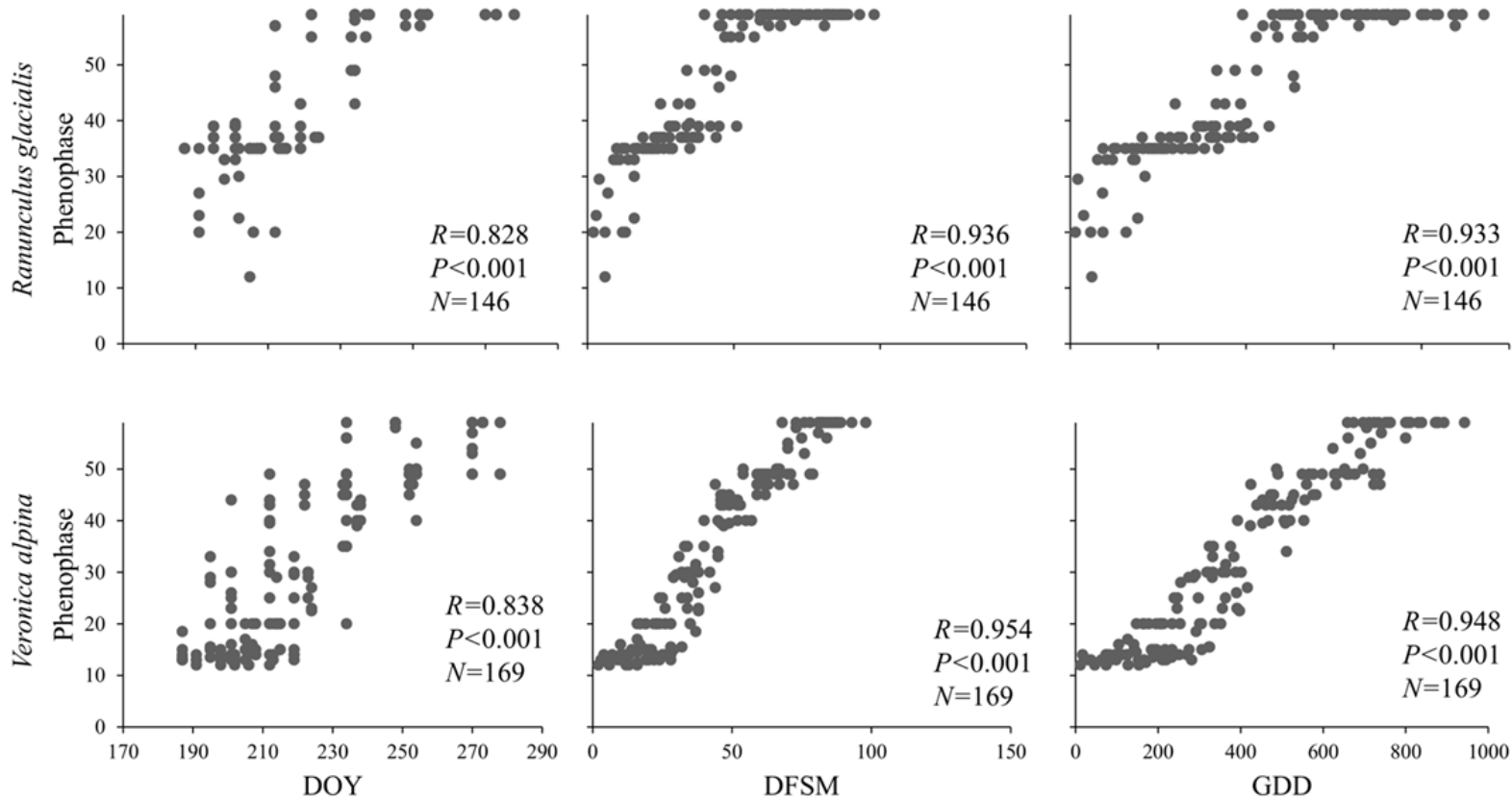

Figure 5 Correlations between phenophases of the debris species and Day Of Year (DOY), Days From Snow Melt (DFSM) and Growing Degree Days (GDD). Every point represents the median phenophase of the 16 subplots at a defined survey date in a single plot and year. Plant phenophases are expressed as a progressive number following the adaptation of BBCH scale (Hack et al. 1992). Spearman's $r$ and significance of the correlation are indicated in every chart.

overlapped. E. minima was the only species insensitive to both DFSM and GDD and, to a lesser extent, A. pentaphyllea and P. alpina, which responded to DFSM only and in a single phenophase, were moderately insensitive. However, most of the species showed a lack of significant interannual variation. Seven species were responsive to DFSM or GDD in at least two phenophases, and for a total of four species (i.e. G. supinum, S. herbacea, A. rupestris, $V$. alpina) the DFSM alone or alternatively DFSM or GDD were fitting in the description of all the three selected phenophases.

\subsection{Interspecific differences}

When analyzing interspecific differences (Figure 6) species had similar responses when considering DFSM and GDD, whereas with a slight difference concerning DOY in phenophase 20 (Flower buds visible) and 50 (Beginning of seed dispersal). The species were equally sorted also in phenophase 35 (Full flowering) for all the variables. The same species showed a recurring distribution throughout most of the phenophases: $R$. glacialis and $S$. herbacea always reached the three phenophases at the lowest values of DOY, DFSM and GDD, together with L. alpina during the flower buds phenophase. E. minima and A. rupestris always achieved the selected phenophases at the highest values of DOY, DFSM and GDD, as well as $G$. supinum during the flower buds and full flowering phenophases and with $A$. pentaphyllaea during the dispersal phenophase. L. alpina had an early onset just for the first phenophase, while the remaining species have an intermediate phenological development.

The model run with species grouped in functional pools did not highlight any significant difference in the achievement of the three phenophases, regardless of the selected variables (Table 3).

\section{Discussion}

\subsection{Interannual differences}

Although Climate Change models foresee a significant snowfall reduction in the Alps, higher elevation areas located in the alpine belt (i.e. above the treeline), such as the Cimalegna plateau, are currently facing a less dramatic change in snow 
Table 2 Comparison of mean values of Day Of Year (DOY), Days From Snow Melt (DFSM) and Growing Degree Days (GDD). The mean value of DOY, DFSM and GDD for each phenophase and species is reported, alongside with the corresponding standard error (Phenophase 20=Flower buds visible, 35=Full flowering, 50=Beginning of seed dispersal). Letters are assigned with Tukey's post-hoc and listed only when there is a significant difference $(P<0.05)$. ns means the difference is non-significant, while the symbol - means there are no values available. Phe. $=$ Phenophase. (-Continued-)

\begin{tabular}{|c|c|c|c|c|c|c|c|c|c|c|c|c|c|c|c|}
\hline $\begin{array}{l}\text { Functional } \\
\text { species pool }\end{array}$ & & \multirow{2}{*}{ Phe. } & \multirow{2}{*}{$\begin{array}{l}\text { Year } \\
2016\end{array}$} & \multicolumn{4}{|c|}{ DOY } & \multicolumn{4}{|c|}{ DFSM } & \multicolumn{4}{|c|}{ GDD } \\
\hline \multirow{36}{*}{$\begin{array}{l}\text { Snowbed } \\
\text { species }\end{array}$} & \multirow{9}{*}{$\begin{array}{l}\text { Alchemilla } \\
\text { pentaphyllea }\end{array}$} & & & 208.5 & \pm & 1.43 & B & 22.4 & \pm & 2.05 & \multirow{3}{*}{ ns } & 221.0 & \pm & 18.21 & B \\
\hline & & \multirow[t]{2}{*}{20} & 2017 & 190.2 & \pm & 1.66 & A & 25.8 & \pm & 2.20 & & 251.6 & \pm & 29.42 & B \\
\hline & & & 2018 & 210.6 & \pm & 4.08 & B & 17.4 & \pm & 1.86 & & 167.5 & \pm & 18.52 & A \\
\hline & & \multirow{3}{*}{35} & 2016 & 227.9 & \pm & 3.84 & B & 41.8 & \pm & 4.11 & B & 413.3 & \pm & 40.63 & B \\
\hline & & & 2017 & 199.8 & \pm & 2.81 & A & 37.8 & \pm & 1.89 & $\mathrm{AB}$ & 371.0 & \pm & 25.79 & $\mathrm{AB}$ \\
\hline & & & 2018 & 225.0 & \pm & 4.25 & B & 31.8 & \pm & 2.19 & A & 316.6 & \pm & 19.02 & A \\
\hline & & \multirow{3}{*}{50} & 2016 & 258.1 & \pm & 1.78 & B & 71.9 & \pm & 2.62 & B & 712.3 & \pm & 20.72 & B \\
\hline & & & 2017 & 237.7 & \pm & 1.73 & B & $75 \cdot 7$ & \pm & 1.43 & A & 760.8 & \pm & 24.58 & B \\
\hline & & & 2018 & 258.6 & \pm & 2.62 & A & 65.4 & \pm & 1.80 & B & 624.9 & \pm & 26.66 & A \\
\hline & \multirow{9}{*}{$\begin{array}{l}\text { Gnaphalium } \\
\text { supinum }\end{array}$} & \multirow{3}{*}{20} & 2016 & 218.7 & \pm & 2.20 & B & 31.4 & \pm & 2.65 & \multirow{3}{*}{ ns } & 300.3 & \pm & 24.21 & $\mathrm{AB}$ \\
\hline & & & 2017 & 198.0 & \pm & 1.57 & A & 30.6 & \pm & 1.39 & & 320.4 & \pm & 18.35 & B \\
\hline & & & 2018 & 219.7 & \pm & 2.75 & B & 26.2 & \pm & 1.76 & & 259.6 & \pm & 18.52 & A \\
\hline & & \multirow{3}{*}{35} & 2016 & 234.5 & \pm & 2.04 & B & $47 \cdot 3$ & \pm & 2.08 & \multirow{3}{*}{ ns } & 465.5 & \pm & 22.86 & \\
\hline & & & 2017 & 212.4 & \pm & 3.59 & A & 47.1 & \pm & 2.14 & & $465 \cdot 3$ & \pm & 24.98 & ns \\
\hline & & & 2018 & 237.5 & \pm & 3.65 & B & 44.0 & \pm & 2.07 & & 429.2 & \pm & 15.82 & \\
\hline & & & 2016 & $249 \cdot 3$ & \pm & 1.11 & $\mathrm{C}$ & 62.0 & \pm & 1.55 & B & 630.1 & \pm & 17.19 & \\
\hline & & 50 & 2017 & 233.5 & \pm & 3.38 & B & 68.3 & \pm & 2.26 & A & 678.1 & \pm & 29.44 & ns \\
\hline & & & 2018 & 256.9 & \pm & 3.43 & A & 64.2 & \pm & 2.35 & $\mathrm{AB}$ & 604.2 & \pm & 20.25 & \\
\hline & & & 2016 & 207.0 & \pm & 2.15 & B & 20.2 & \pm & 1.99 & & 194.4 & \pm & 25.43 & \\
\hline & & 20 & 2017 & 193.3 & \pm & 1.98 & A & 27.2 & \pm & 3.23 & ns & 261.8 & \pm & 26.85 & ns \\
\hline & & & 2018 & 211.0 & \pm & 3.89 & B & 16.7 & \pm & 2.58 & & 156.2 & \pm & 26.30 & \\
\hline & & & 2016 & 238.3 & \pm & 0.78 & $\mathrm{C}$ & 51.5 & \pm & 1.28 & B & 510.0 & \pm & 13.74 & C \\
\hline & $\begin{array}{l}\text { Luzu } \\
\text { alpin }\end{array}$ & 35 & 2017 & 204.9 & \pm & $3 \cdot 35$ & B & 38.7 & \pm & 3.64 & A & 407.1 & \pm & 34.41 & B \\
\hline & & & 2018 & 225.5 & \pm & 3.60 & A & 31.3 & \pm & 2.10 & A & 307.0 & \pm & 20.35 & A \\
\hline & & & 2016 & 259.7 & \pm & 1.98 & B & 73.0 & \pm & 2.01 & & 701.3 & \pm & 20.95 & \\
\hline & & 50 & 2017 & 234.9 & \pm & 2.12 & A & 68.7 & \pm & 2.49 & ns & 697.4 & \pm & 30.07 & ns \\
\hline & & & 2018 & 257.0 & \pm & 2.28 & B & 62.7 & \pm & 2.37 & & $589 \cdot 3$ & \pm & 29.38 & \\
\hline & & & 2016 & 203.7 & \pm & 1.59 & B & 14.9 & \pm & 2.22 & & 141.4 & \pm & 22.75 & B \\
\hline & & 20 & 2017 & 188.5 & \pm & 1.50 & A & 13.5 & \pm & 1.50 & ns & 118.0 & \pm & 19.00 & $\mathrm{AB}$ \\
\hline & & & 2018 & 205.7 & \pm & 2.54 & B & 12.2 & \pm & 1.06 & & $105 \cdot 3$ & \pm & 10.82 & A \\
\hline & & & 2016 & 211.6 & \pm & 1.90 & B & 24.3 & \pm & 1.77 & $\mathrm{AB}$ & 233.8 & \pm & 19.62 & \\
\hline & Salix herbacea & 35 & 2017 & 193.8 & \pm & 1.19 & A & 26.2 & \pm & 1.99 & B & 248.8 & \pm & 23.12 & ns \\
\hline & & & 2018 & 214.1 & \pm & 2.48 & B & 20.6 & \pm & 1.39 & A & 198.2 & \pm & 15.85 & \\
\hline & & & 2016 & 240.8 & \pm & 1.25 & B & 53.6 & \pm & 1.63 & & 535.1 & \pm & 20.51 & \\
\hline & & 50 & 2017 & 216.9 & \pm & 2.46 & A & 51.6 & \pm & 2.74 & ns & 514.9 & \pm & 24.09 & ns \\
\hline & & & 2018 & $245 \cdot 5$ & \pm & 3.18 & B & 52.0 & \pm & 1.97 & & 500.2 & \pm & 19.33 & \\
\hline & & & 2016 & 232.9 & \pm & 2.32 & B & 46.2 & \pm & 2.46 & & 453.2 & \pm & 26.54 & B \\
\hline & & 20 & 2017 & 206.4 & \pm & 4.81 & A & 41.1 & \pm & 3.29 & ns & $453 \cdot 3$ & \pm & 25.08 & B \\
\hline & & & 2018 & 231.8 & \pm & $4 \cdot 37$ & B & 39.2 & \pm & 2.79 & & 372.9 & \pm & 30.82 & A \\
\hline & & & 2016 & 250.0 & \pm & 2.17 & B & 63.3 & \pm & 2.35 & & 642.5 & \pm & 27.93 & B \\
\hline species & rupestris & 35 & 2017 & 222.0 & \pm & 4.99 & A & 56.8 & \pm & 5.00 & ns & 604.3 & \pm & 21.47 & B \\
\hline & & & 2018 & 246.2 & \pm & 4.80 & B & 53.6 & \pm & 2.89 & & 516.9 & \pm & 20.37 & A \\
\hline & & & 2016 & 266.9 & \pm & 0.44 & B & 80.2 & \pm & 1.38 & & 739.7 & \pm & 20.64 & B \\
\hline & & 50 & 2017 & 231.9 & \pm & 5.97 & A & 66.6 & \pm & 6.30 & ns & 710.0 & \pm & 28.11 & B \\
\hline & & & 2018 & 258.6 & \pm & 4.23 & B & 66.0 & \pm & 2.26 & & 627.0 & \pm & 14.94 & A \\
\hline
\end{tabular}

(-To be continued-) 
Table 2 Comparison of mean values of Day Of Year (DOY), Days From Snow Melt (DFSM) and Growing Degree Days (GDD).The mean value of DOY, DFSM and GDD for each phenophase and species is reported, alongside with the corresponding standard error (Phenophase 20=Flower buds visible, 35=Full flowering, 50=Beginning of seed dispersal). Letters are assigned with Tukey's post-hoc and listed only when there is a significant difference $(P<0.05)$. ns means the difference is non-significant, while the symbol - means there are no values available. Phe.= Phenophase.(-Continued-)

\begin{tabular}{|c|c|c|c|c|c|c|c|c|c|c|c|c|c|c|c|}
\hline $\begin{array}{l}\text { Functional } \\
\text { species pool }\end{array}$ & Species & & \multirow{2}{*}{$\begin{array}{l}\text { Year } \\
2016\end{array}$} & \multicolumn{4}{|c|}{ DOY } & \multicolumn{4}{|c|}{ DFSM } & \multicolumn{4}{|c|}{ GDD } \\
\hline & \multirow{9}{*}{$\begin{array}{l}\text { Euphrasia } \\
\text { minima }\end{array}$} & \multirow{3}{*}{20} & & 224.1 & \pm & 1.73 & B & 36.9 & \pm & 2.25 & $\mathrm{C}$ & 354.9 & \pm & 23.07 & B \\
\hline & & & 2017 & 206.4 & \pm & 3.97 & A & 41.1 & \pm & 2.53 & B & 425.9 & \pm & 27.99 & A \\
\hline & & & 2018 & 226.5 & \pm & $3 \cdot 33$ & B & 33.0 & \pm & 1.54 & A & 328.0 & \pm & 13.28 & B \\
\hline & & \multirow{3}{*}{35} & 2016 & 237.4 & \pm & 0.18 & B & 50.1 & \pm & 1.36 & B & 496.2 & \pm & 16.71 & B \\
\hline & & & 2017 & 222.5 & \pm & $3 \cdot 31$ & A & $57 \cdot 3$ & \pm & 2.56 & A & 571.9 & \pm & 30.49 & A \\
\hline & & & 2018 & 240.5 & \pm & 3.76 & B & 47.0 & \pm & 1.92 & B & 454.8 & \pm & 13.02 & B \\
\hline & & \multirow{3}{*}{50} & 2016 & 262.1 & \pm & 0.66 & B & 74.9 & \pm & 1.43 & $\mathrm{AB}$ & 712.3 & \pm & 18.47 & $\mathrm{C}$ \\
\hline & & & 2017 & 243.1 & \pm & 1.30 & A & 77.9 & \pm & 2.25 & B & 773.0 & \pm & 25.82 & B \\
\hline & & & 2018 & 262.1 & \pm & 2.59 & B & 69.4 & \pm & 0.69 & A & 649.2 & \pm & 12.63 & A \\
\hline & \multirow{9}{*}{$\begin{array}{l}\text { Leucanthemop } \\
\text { sis alpina }\end{array}$} & \multirow{3}{*}{20} & 2016 & 204.1 & \pm & 1.67 & B & 16.6 & \pm & 2.92 & B & 157.8 & \pm & 29.60 & B \\
\hline & & & 2017 & 189.0 & \pm & 2.00 & A & 20.0 & \pm & 8.00 & $\mathrm{AB}$ & 188.5 & \pm & 89.50 & $\mathrm{AB}$ \\
\hline & & & 2018 & 200.2 & \pm & $3 \cdot 34$ & $\mathrm{AB}$ & $7 \cdot 7$ & \pm & 1.91 & A & 63.5 & \pm & 14.91 & A \\
\hline & & \multirow{3}{*}{35} & 2016 & 225.5 & \pm & 2.64 & B & 38.2 & \pm & 2.65 & \multirow{6}{*}{ ns } & 370.0 & \pm & 27.51 & \multirow{3}{*}{ ns } \\
\hline & & & 2017 & 205.9 & \pm & 3.60 & A & 40.9 & \pm & 1.62 & & 391.3 & \pm & 26.94 & \\
\hline & & & 2018 & 227.0 & \pm & 3.44 & B & 34.5 & \pm & 1.45 & & 349.7 & \pm & 15.80 & \\
\hline & & \multirow{3}{*}{50} & 2016 & 250.6 & \pm & 1.90 & B & 63.4 & \pm & 2.72 & & 638.1 & \pm & 28.69 & \\
\hline & & & 2017 & 224.6 & \pm & 3.45 & A & 59.6 & \pm & 1.85 & & 582.9 & \pm & 32.35 & ns \\
\hline & & & 2018 & 249.7 & \pm & 2.86 & B & 57.2 & \pm & 1.17 & & 547.4 & \pm & 17.65 & \\
\hline & \multirow{9}{*}{ Poa alpina } & & 2016 & 211.1 & \pm & 2.42 & B & 23.8 & \pm & 2.61 & & 228.6 & \pm & 25.77 & B \\
\hline & & 20 & 2017 & 192.6 & \pm & 2.03 & A & 25.1 & \pm & 1.06 & ns & 241.9 & \pm & 17.16 & B \\
\hline & & & 2018 & 213.3 & \pm & 3.32 & B & 19.8 & \pm & 2.03 & & 189.4 & \pm & 19.27 & A \\
\hline & & & 2016 & 238.8 & \pm & 2.55 & $\mathrm{C}$ & 51.5 & \pm & 2.21 & B & 530.0 & \pm & 23.23 & B \\
\hline & & 35 & 2017 & 204.0 & \pm & 2.22 & B & 38.8 & \pm & 1.62 & A & 380.6 & \pm & 11.13 & A \\
\hline & & & 2018 & 229.3 & \pm & 2.96 & A & 35.8 & \pm & 2.28 & A & 356.4 & \pm & 20.44 & A \\
\hline & & & 2016 & 255.7 & \pm & 2.23 & B & 68.4 & \pm & 2.45 & B & 680.7 & \pm & 18.63 & B \\
\hline & & 50 & 2017 & 214.4 & \pm & 3.10 & A & 49.1 & \pm & 2.21 & A & 487.1 & \pm & 17.80 & A \\
\hline & & & 2018 & 246.6 & \pm & 4.75 & B & 53.1 & \pm & 3.66 & A & 508.3 & \pm & 28.29 & A \\
\hline & & & 2016 & 209.3 & \pm & - & - & 23.3 & \pm & - & - & 222.2 & \pm & & - \\
\hline & & 20 & 2017 & 191.0 & \pm & - & - & 41.0 & \pm & - & - & 339.0 & \pm & - & - \\
\hline & & & 2018 & 203.8 & \pm & 4.48 & - & 8.3 & \pm & 2.59 & - & 65.1 & \pm & 24.40 & - \\
\hline & & & 2016 & 206.0 & \pm & 1.85 & B & 19.3 & \pm & 2.43 & & 186.0 & \pm & 23.71 & $\mathrm{AB}$ \\
\hline & Ranunculus & 35 & 2017 & 188.6 & \pm & 1.07 & A & 24.7 & \pm & 3.72 & ns & 227.9 & \pm & 32.88 & B \\
\hline & & & 2018 & 210.3 & \pm & 2.49 & B & 17.7 & \pm & 1.15 & & 153.1 & \pm & 19.02 & A \\
\hline & & & 2016 & 232.5 & \pm & 0.29 & B & 45.8 & \pm & 1.62 & & 449.3 & \pm & 17.84 & $\mathrm{AB}$ \\
\hline & & 50 & 2017 & 207.7 & \pm & 3.88 & A & 43.9 & \pm & 3.37 & ns & 459.7 & \pm & 20.39 & B \\
\hline Debris & & & 2018 & 232.6 & \pm & 2.49 & B & 40.0 & \pm & 1.94 & & 397.6 & \pm & 21.11 & A \\
\hline species & & & 2016 & 213.6 & \pm & 2.31 & B & 26.3 & \pm & 2.77 & & 253.2 & \pm & 28.71 & \\
\hline & & 20 & 2017 & 195.6 & \pm & 1.95 & A & 30.4 & \pm & 1.68 & ns & 289.5 & \pm & 19.71 & ns \\
\hline & & & 2018 & 217.6 & \pm & 3.20 & B & 24.1 & \pm & 2.18 & & 235.5 & \pm & 23.72 & \\
\hline & & & 2016 & 231.0 & \pm & 0.76 & B & 43.7 & \pm & 1.68 & B & 427.4 & \pm & 18.02 & \\
\hline & Veronica & 35 & 2017 & 208.5 & \pm & 2.54 & A & 43.3 & \pm & 0.92 & B & 426.6 & \pm & 13.43 & ns \\
\hline & & & 2018 & 230.9 & \pm & 3.14 & B & 37.4 & \pm & 2.03 & A & 372.2 & \pm & 19.63 & \\
\hline & & & 2016 & 255.8 & \pm & 0.90 & B & 68.5 & \pm & 1.57 & & 681.3 & \pm & 17.31 & B \\
\hline & & 50 & 2017 & 230.5 & \pm & 2.88 & A & 65.3 & \pm & 1.97 & ns & 650.5 & \pm & 26.41 & $\mathrm{AB}$ \\
\hline & & & 2018 & 253.5 & \pm & 2.09 & B & 62.0 & \pm & 1.96 & & 590.4 & \pm & 23.28 & A \\
\hline
\end{tabular}

dynamics than lower elevation areas located in the mountain and subalpine belts (IPCC 2019a). Moreover, the timespan of this study was not sufficient to witness evidence of Climate Change. Nevertheless, we detected a pronounced interannual variability especially in the date of 


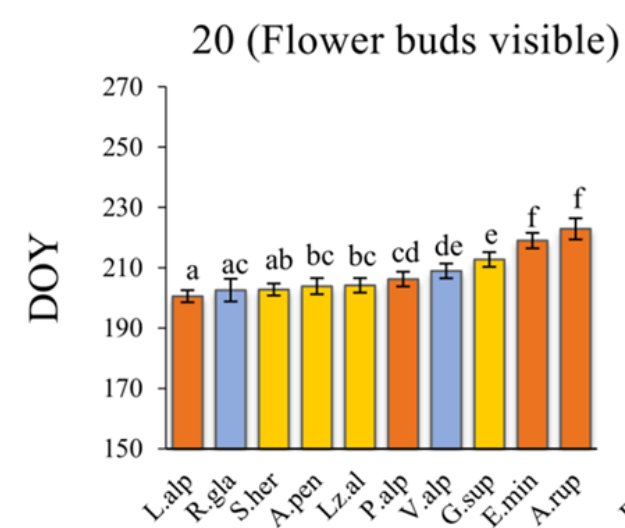

35 (Full flowering)

50 (Seed dispersal)
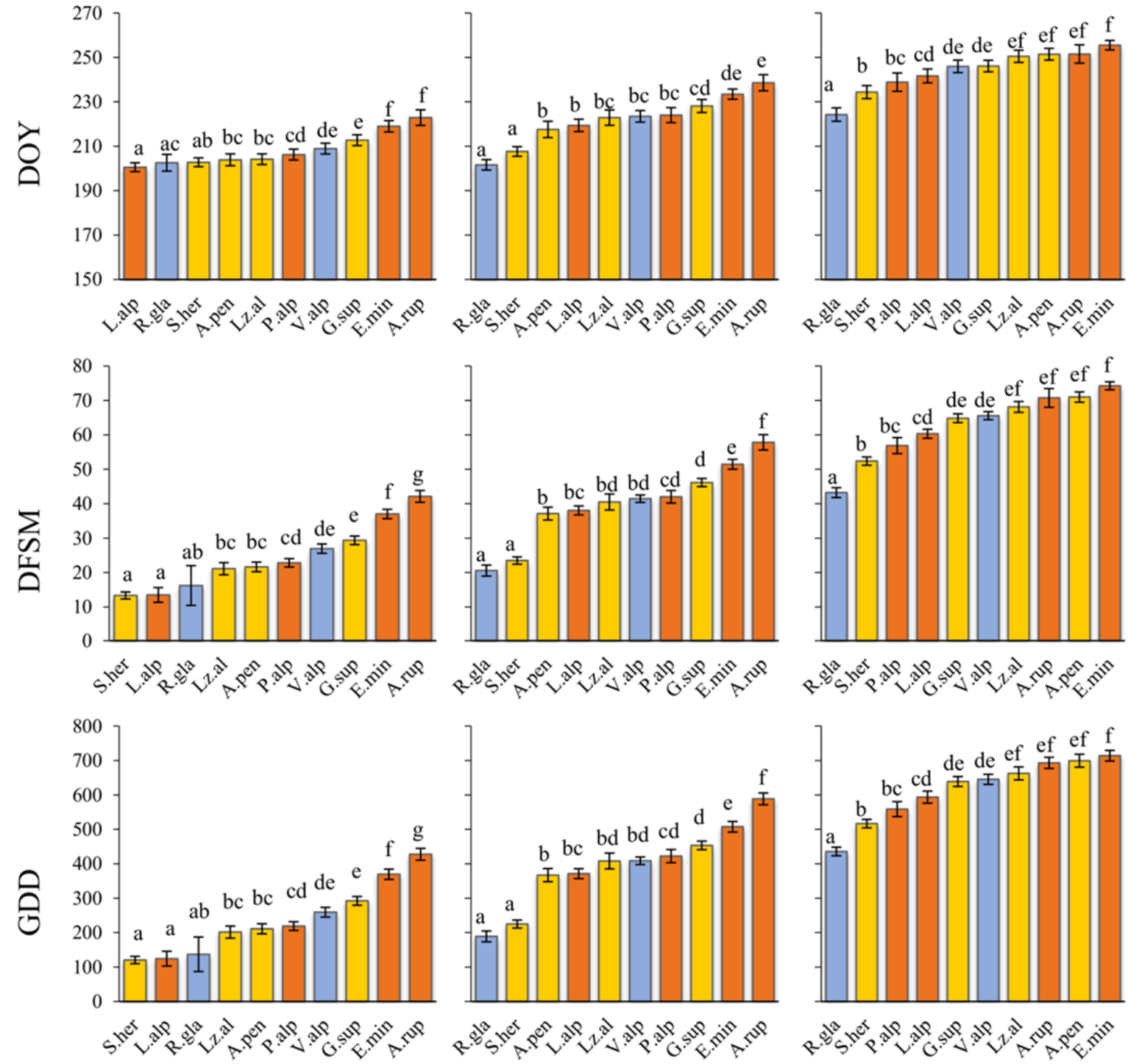

Figure 6 Interspecific differences through three selected phenophases and Day Of Year (DOY), Days From Snow Melt (DFSM) and Growing Degree Days (GDD). The chart is referred to all the monitoring years. The height of the column represents the mean value of DOY, DFSM or GDD at which the given phenophase was reached, together with its corresponding standard error. Different letters highlight significant differences among species (letters assigned with Tukey's post-hoc tests for $P<0.05$ ). The colors identify the three functional species pools: blue: debris species; yellow: snowbed species; red: grassland species. A.rup=Agrostis rupestris A.pen=Alchemilla pentaphyllea; E.min=Euphrasia minima; G.sup=Gnaphalium supinum; L.alp=Leucanthemopsis alpina; Lz.al=Luzula alpinopilosa; P.alp=Poa alpina; R.gla=Ranunculus glacialis; S.her=Salix herbacea; V.alp=Veronica alpina .

snowmelt, which ranged up to one month over the three years of monitoring. Although the effect of microtopography determined some consistent variations in temperature and snowmelt across the plots, the weight of interannual differences was overwhelming on the general trend which set apart year 2017 from 2016 and 2018, enabling us to explore different scenarios. The snowmelt shift was mainly caused by various conditions of the snowpack, which can last longer according to spring temperature and snowfall dynamics during winter. For instance, the consistent amount of precipitation during winter 2017-2018 caused a thicker snowpack, resulting in a later snowmelt, while the relatively dry winter 2016-2017, with snowfall accumulation centered in DecemberJanuary led to an early snowmelt. The change in the snowmelt date resulted in a broad variation of the beginning of the vegetative season since, in snowbed communities, the onset of the first 
Table 3 Differences through the selected phenophases and variables in terms of functional species pools. Mean value of Day Of Year (DOY), Days From Snow Melt (DFSM) and Growing Degree Days (GDD) for each pool is expressed alongside with the corresponding standard error.

\begin{tabular}{|c|c|c|c|c|c|c|c|c|c|c|c|c|c|}
\hline \multirow{2}{*}{\multicolumn{2}{|c|}{$\begin{array}{l}\text { Functional species } \\
\text { pools }\end{array}$}} & \multicolumn{12}{|c|}{ Phenophase } \\
\hline & & \multicolumn{4}{|c|}{ Flower buds visible } & \multicolumn{4}{|c|}{ Full flowering } & \multicolumn{4}{|c|}{ Beginning of seed dispersal } \\
\hline Variable & Group & Mean & & S.E. & & Mean & & S.E. & & Mean & & S.E. & \\
\hline \multirow{3}{*}{ DOY } & Debris & 203 & \pm & 8.6 & \multirow{3}{*}{ ns } & 213 & \pm & 9.3 & \multirow{3}{*}{ ns } & 236 & \pm & 9.4 & \multirow{3}{*}{ ns } \\
\hline & Snowbed & 204 & \pm & $7 \cdot 4$ & & 219 & \pm & 8.2 & & 246 & \pm & 8.4 & \\
\hline & Grassland & 211 & \pm & $7 \cdot 4$ & & 229 & \pm & 8.2 & & 247 & \pm & 8.4 & \\
\hline \multirow{3}{*}{ DFSM } & Debris & 22 & \pm & 6.3 & \multirow{3}{*}{ ns } & 31 & \pm & 6.6 & \multirow{3}{*}{ ns } & 54 & \pm & 6.2 & \multirow{3}{*}{ ns } \\
\hline & Snowbed & 22 & \pm & 4.7 & & 37 & \pm & 5.0 & & 64 & \pm & 4.6 & \\
\hline & Grassland & 29 & \pm & 4.7 & & 47 & \pm & 5.0 & & 66 & \pm & 4.6 & \\
\hline \multirow{3}{*}{ GDD } & Debris & 199 & \pm & 67.4 & \multirow{3}{*}{ ns } & 298 & \pm & 69.5 & \multirow{3}{*}{ ns } & 538 & \pm & 60.0 & \multirow{3}{*}{ ns } \\
\hline & Snowbed & 209 & \pm & 51.0 & & 360 & \pm & 52.4 & & 625 & \pm & 46.0 & \\
\hline & Grassland & 288 & \pm & 51.0 & & 473 & \pm & 52.4 & & 640 & \pm & 45.9 & \\
\hline
\end{tabular}

phenophases is believed to be strongly dependent on snowmelt (Körner 2003; Lessard-Therrien et al. 2014; Wang et al. 2015). Indeed, findings from the correlations underlined how climatic differences among 2016, 2017 and 2018 heavily affected the whole temporal distribution of the phenological cycle. Despite the high correlation values between plant phenophases and DOY, DFSM or GDD, the first variable had always a lower Spearman's $r$ than the other two. The phenophases of most of the species were strongly correlated to DFSM and slightly less correlated to GDD with two exceptions, having nearly identical values. Photoperiod, which is proxied by DOY, is frequently referred to as an important cue in the timing of phenological events since it can help controlling extremely early or late development (Hülber et al. 2010; Steltzer and Post 2009). Our results though addressed us towards the hypothesis of the relatively poor relevance of photoperiod as a single factor in the prediction of the phenological cycle of alpine plants when faced with the chance of interannual variability.

The interactions between photoperiodism, temperature, and alpine plant phenology has been investigated with an experiment by Keller and Körner (2003), who highlighted a strong dependence of flowering on photoperiod for most of the species (seven of them are in common with the present study). However, whereas at longer day length flowering dynamics were mostly influenced by photoperiodism, at shorter day length species were more sensitive to temperature regimes. Moreover, some species were found to be insensitive both to light and temperature ( $R$. glacialis), thus possibly influenced by different ecological factors such as snow disappearance. Further links between flowering phenology and photoperiodism were studied by Larl et al. (2006). This study focused on the pioneer species Saxifraga oppositifolia, proving how the initiation of the flower primordia was controlled solely by photoperiod, while the time of flowering, seed development, and shoot growth depended on the date of snowmelt. Regarding arctic, sub-arctic and nival biomes, the date of snowmelt is widely recognized to have an overwhelming effect on plant species onset (Totland and Alatalo 2002; Wipf 2009).

While the effect of DOY always expressed a high variability throughout the years, with a consistent trend that identified 2017 as fairly different from 2016 and 2018, the effects of DFSM and GDD were less variable among years. Indeed, while considering DFSM and GDD, we observed for most of the species the lack of significant differences amongst the three monitoring years. This result led us to recognize these two variables better predictors of the phenological development even across very dissimilar vegetative seasons. When the three years of the experiment were modelled together, we found most of the species appearing more strongly controlled by DFSM and GDD than by DOY, even if the trend was not consistent throughout all the species and phenophases. If such a finding highlights the presence of some fairly good predictors of the phenological cycle of the overall plant community, on the other hand it reflects some profound differences in the behavior of different alpine tundra species. Indeed, the study of plant phenology should address each species individually since either an overall approach and grouping in functional species pool would not grant reliable results. For some species (A. rupestris, $R$. glacialis and to some extent $P$. alpina and A. pentaphyllea) 
we were able to identify DFSM as a major driver of the phenological development. For most of the species, phenology seems to be related to both DFSM and GDD depending on the selected phenophase. For E. minima, the only studied annual species, we were not able to identify which variable best suited the description of the phenological cycle, even though results from the correlation analyses stressed how DFSM and GDD are always slightly superior to DOY. Likely, widespread annual species will persist in the next changing climate due to the ability to quickly adapt their phenology in order to track ideal seasonal conditions (Hereford et al. 2017). From our study, E. minima phenophases seemed not to rely on a specific temporal and climate-related variable. However, since a single species is not sufficient to assess the response path of the whole annual species group, we suggest as a forthcoming step to possibly analyze a larger number of plant annual species since the population dynamics between opportunistic widespread species and specialists will be crucial in shaping the future of such environments.

\subsection{Interspecific differences}

Literature is mostly concordant on behalf of the potential fragmentation and disappearance of snowbeds in the current Climate Change scenario due to alteration in snow dynamics (Hulber et al. 2011; Legault et al. 2015; Sedlacek et al. 2015) and input of competitive, non-specialist vegetation from the nearby habitats (Heegard and Vandvik 2004; Komac et al. 2015). Species with phytosociological optimum in different associations tend to show a wide range of strategies; snowbed specialists for instance are generally poor competitors (Kudo and Suzuki 1999; Onipchenko et al. 2004). They are more likely to struggle in shifting their phenological cycle when compared with opportunistic grassland species or pioneer species of the rocky outcrops (Gugger et al. 2015; Carbognani et al. 2014). Nevertheless, no significant difference emerged between snowbed, grassland and debris species, displaying how the phenological development is not affected by functional species pool and should be rather explored at a species level. When we tested in detail interspecific differences, the variability was significant. Such variability was expressed in a consistent tendency of each species to reach phenophases with a certain advance or delay, while confronted with the others. Due to the high number of species it was not possible to identify a consistent threshold value in order to separate them in categories. Even though such an objective value could not be found, observation of the charts suggested a well expressed pattern that led us to the identification of three phenological behaviors. We defined "early species" as the ones which were able to reach all the selected phenophases quite in advance, as opposed to "late species" which always achieved phenophases with a certain delay. Species with an in-between behavior and the tendency to sway in the middle of the first two groups were defined "intermediate". This classification could be applied to all of our three variables with some minor variations. Overall, DFSM and GDD show more similarities since the behavior did not change depending on the selected variable nor on the phenophase. DOY exhibited a solid consistency with the other variables only when examined on the phenophase of full flowering. The variations illustrated in the remaining phenophases are mostly referred to the category of intermediate species, namely the ones not showing a strongly polarized behavior. Species with a pronounced early or late behavior in the achievement of the phenophases (S. herbacea, R. glacialis, E. minima, $A$. rupestris) were not affected by said variations, but they maintained respectively their early or late conduct. The occurrence of different behaviors represents the practice of different strategies, each of which bearing benefits and disadvantages. In case of an early disappearance of the snow layer, an extremely fast onset could determine exposure to structural damages, especially for flower buds, linked to spring frosts (Inouye 2008; Klein et al. 2018; Vitasse et al. 2018). On the other hand, an exaggerated delay in the occurrence of late phenophases could lead to the failure to complete the reproductive cycle. Our findings highlighted not only how relevant the interspecific differences are when analyzing plant phenology, but also how the selection of a specific season-related variable could have a major role in describing the plant phenological cycle. Further research, based on similar comprehensive methods for the monitoring of alpine plant phenology, appears advisable to 
take in account additional environmental factors (for instance chilling, soil nutrients or precipitation) to contribute to a more accurate modelling of the phenological behavior.

\section{Conclusions}

The snowmelt date and, to a certain extent, the thermal sum, resulted effective predictors for the phenophases of most of the species under consideration. The photoperiod, on the other hand, proved to be a less valuable predictor due to the failure to offset interannual variability. The synchronization of the phenological cycle with the disappearance of the snowpack and the temperatures is an evidence of the remarkable adaptation of these species to the peculiar conditions of the snowbed environment. Forthcoming changes in temperature and snow dynamics will have an impact on the vegetation communities in the long term. However, we highlighted the relevance of considering each species individually, since we reported major differences in the phenological behavior of a relatively homogenous plant community. The consistent achievement of all the phenophases at lower or higher values of DFSM and GDD determined the classification in three distinct groups. Species were defined early, late or intermediate regardless of their functional pools, and each of these strategies could bear benefits or

\section{References}

Aeschimann D, Lauber K and Dessinateur AM (2004) Flora alpina: atlante delle 4500 piante vascolari delle Alpi (Alpine Flora: an atlas of the 4500 vascular plants of the Alps). Zanichelli, Bologna. (In Italian)

Beerling DJ (1998) Salix herbacea L. Journal of Ecology 86: 872-895.

Björk RG, Molau U (2007) Ecology of alpine snowbeds and the impact of global change. Arctic, Antarctic, and Alpine Research 39(1): 34-43. https://doi.org/10.1657/1523-0430 (2007)39[34:EOASAT]2.0.CO;2

Carbognani M, Petraglia A and Tomaselli M (2012) Influence of snowmelt time on species richness, density and production in a late snowbed community. Acta Oecologica 43: 113-120.

https://doi.org/10.1016/j.actao.2012.06.003

Carbognani M, Tomaselli M, and Petraglia A (2014) Current vegetation changes in an alpine late snowbed community in the south-eastern Alps (N-Italy). Alpine Botany 124: 105-113. https://doi.org/10.1007/s00035-014-0135-x

Carbognani M, Bernareggi G, Perucco F, et al. (2016) Microclimatic controls and warming effects on flowering time in alpine snowbeds. Oecologia 182: 573-585.

https://doi.org/10.1007/s00442-016-3669-3

Ding MJ, Li LH, Nie Y, et al. (2016) Spatio-temporal variation of spring phenology in Tibetan Plateau and its linkage to climate change from 1982 to 2012. Journal of Mountain Science 13 (1): disadvantages. While early species could profit from elongation of the season, they could also incur in the risk of frost damages to the reproductive structures. Late species will avoid such risks but could fail in concluding the phenological cycle.

\section{Acknowledgments}

We thank prof. Pier Giorgio Montarolo, director of Istituto Angelo Mosso, which was a fundamental operating base for our fieldwork. This study was funded by MonteRosa20oo s.p.a., which we thank for supporting the monitoring project throughout its course. Open Access funding provided by Università degli Studi di Torino within the CRUICARE Agreement.

Electronic supplementary material: Supplementary material (Appendix 1) is available in the online version of this article at https://doi.org/ 10.1007/s11629-020-6079-2

Open Access This article is distributed under the terms of the Creative Commons Attribution 4.0 International License (http://creativecommons. org/licenses/by/4.0/), which permits unrestricted use, distribution, and reproduction in any medium, provided you give appropriate credit to the original author(s) and the source, provide a link to the Creative Commons license, and indicate if changes were made.

83-94. https://doi:10.1007/s11629-015-3600-o

Ernakovich JG, Hopping KA, Berdanier AB, et al. (2014) Predicted responses of arctic and alpine ecosystems to altered seasonality under climate change. Global Change Biology 20: 3256-3269. https://doi.org/10.1111/gcb.12568

Filippa G, Cremonese E, Galvagno M, et al. (2015) Five years of phenological monitoring in a mountain grassland: interannual patterns and evaluation of the sampling protocol. International Journal of Biometeorology 59(12): 1927-1937. https://doi.org/10.1007/s00484-015-0999-5

Gugger S, Kesselring H, Stöcklin J and Hamann E (2015) Lower plasticity exhibited by high- versus mid-elevation species in their phenological responses to manipulated temperature and drought. Annals of Botany 116: 953-962. https://doi.org/10.1093/aob/mcv155

Freppaz M, Celi L, Marchelli M, Zanini E (2008) Snow removal and its influence on temperature and $\mathrm{N}$ dynamics in alpine soils (Vallee d'Aoste, northwest Italy). Journal of Plant Nutrition and Soil Science 171(5): 672-680. https://doi.org/10.1002/jpln.200700278

Freppaz M, Filippa G, Caimi A, et al. (2010) Soil and plant characteristics in the alpine tundra (NW Italy). Tundras: Vegetation, Wildlife and Climate Trends. Nova Publishers. pp 81-110.

Hack H, Bleiholder H, Buhr L, et al. (1992) Einheitliche codierung der phänologischen entwicklungsstadien mono- 
und dikotyler pflanzen-erweiterte BBCH-Skala, Allgemein (A uniform code for phenological growth stages of mono-and dicotyledonous plants. Extended BBCH Scale, General). Nachrichtenblatt des Deutschen Pflanzenschutzdienstes 44: 265270. (In German)

Heegaard E and Vandvik V (2004) Climate change affects the outcome of competitive interactions - An application of principal response curves. Oecologia 139: 459-466.

https://doi.org/10.1007/so0442-004-1523-5

Hereford J, Schmitt J and Ackerly DD (2017) The Seasonal Climate Niche Predicts Phenology and Distribution of an Ephemeral Annual Plant, Mollugo Verticillata. Journal of Ecology 105(5): 1323-334. https://doi.org/10.1111/1365-2745.12739

Huelber K, Gottfried M, Pauli H, et al. (2006) Phenological responses of snowbed species to snow removal dates in the Central Alps: Implications for climate warming. Arctic, Antarctic, and Alpine Research 38: 99-103.https://doi.org/10. 1657/1523-0430(2006)038[0099:PROSST]2.0.CO;2

Hülber K, Winkler M and Grabherr G (2010) Intraseasonal climate and habitat-specific variability controls the flowering phenology of high alpine plant species. Functional Ecology 24: 245-252. https://doi.org/10.1111/j.1365-2435.2009.01645.x

Hülber K, Bardy K and Dullinger S (2011) Effects of snowmelt timing and competition on the performance of alpine snowbed plants. Perspectives in Plant Ecology, Evolution and Systematics 13: 15-26.https://doi.org/10.1016/j.ppees.2011.01.001

Inouye DW (2008) Effects of climate change on phenology, frost damage, and floral abundance of montane wildflowers. Ecology 89: 353-362. https://doi.org/10.189o/o6-2128.1

IPCC (2019a) Climate change and land. Research Handbook on Climate Change and Agricultural Law 423-449.

https://doi.org/10.4337/9781784710644

IPCC (2019b) The Ocean and Cryosphere in a Changing Climate. https://www.ipcc.ch/srocc/

Isard SA (1986) Factors influencing soil moisture and plant community distribution on niwot ridge, front range, Colorado, U.S.A.. Arctic and Alpine Research 18(1): 83-96.

https://doi.org/10.1080/00040851.1986.12004065

Kawai Y and Kudo G (2011) Local differentiation of flowering phenology in an alpine-snowbed herb Gentiana nipponica. Botany 89(6): 361-367. https://doi.org/10.1139/b11-024

Keller F and Körner C (2003) The role of photoperiodism in alpine plant development. Arctic, Antarctic, and Alpine Research 35(3): 361-368. https://doi.org/10.1657/1523-0430 (2003)035[0361:TROPIA]2.0.CO;2

Khorsand Rosa R, Oberbauer SF, Starr G, et al. (2015) Plant phenological responses to a long-term experimental extension of growing season and soil warming in the tussock tundra of Alaska. Global Change Biology 21: 4520-4532. https://doi.org/10.1111/gcb.13040

Kimball KD, Davis ML, Weihrauch DM, et al. (2014) Limited alpine climatic warming and modeled phenology advancement for three alpine species in the Northeast United States. American Journal of Botany 101: 1437-1446. https://doi.org/10.3732/ajb.1400214

Klein G, Rebetez M, Rixen C and Vitasse Y (2018) Unchanged risk of frost exposure for subalpine and alpine plants after snowmelt in Switzerland despite climate warming. International Journal of Biometeorology 62: 1755-1762. https://doi.org/10.1007/s00484-018-1578-3

Komac B, Pladevall C, Peñuelas J, et al. (2015) Variations in functional diversity in snowbed plant communities determining snowbed continuity. Plant Ecology 216: 12571274. https://doi.org/10.1007/s11258-015-0506-4

Körner C (2003) Alpine Plant Life: Functional Plant Ecology of High Mountain Ecosystems. Springer Science \& Business Media. Springer.

Kudo G and Suzuki S (1999) Flowering phenology of alpine plant communities along a gradient of snowmelt timing. Polar Bioscience 12: 100-113. http://id.nii.ac.jp/1291/o0006135/

Landolt E, Bäumler B, Ehrhardt A, et al. (2010) Flora indicativa $=$ Ecological inicator values and biological attributes of the flora of Switzerland and the Alps. Haupt Verlag. http://edoc.unibas.ch/dok/A4742818

Larl I and Wagner $J$ (2006) Timing of reproductive and vegetative development in Saxifraga oppositifolia in an alpine and a subnival climate. Plant Biology 8: 155-166. https://doi.org/10.1055/s-2005-872888

Lessard-Therrien M, Bolmgren $\mathrm{K}$ and Davies TJ (2014) Predicting flowering phenology in a subarctic plant community. Botany 92(10): 749-756.

https://doi.org/10.1139/cjb-2014-0026

Lonati M, Moot DJ, Aceto P, et al. (2009) Thermal time requirements for germination, emergence and seedling development of adventive legume and grass species. New Zealand Journal of Agricultural Research 52: 17-29. https://doi.org/10.1080/00288230909510485

LTER Italia (2020) Long Term Ecological Research, Italia. http://www.lteritalia.it, accessed 20 January 2020.

Magnani A, Viglietti D, Godone D, et al. (2017) Interannual variability of soil $\mathrm{N}$ and $\mathrm{C}$ forms in response to snow -cover duration and pedoclimatic conditions in alpine tundra, northwest Italy. Arctic, Antarctic, and Alpine Research 49 (2): 227-242. https://doi.org/ 10.1657/AAAR0016-037

Mulder CPH, Iles DT and Rockwell RF (2017) Increased variance in temperature and lag effects alter phenological responses to rapid warming in a subarctic plant community. Global Change Biology 23: 801-814. https://doi.org/10.1111/gcb.13386

Ninot JM, Grau O, Carrillo E, et al. (2013) Functional plant traits and species assemblage in pyrenean snowbeds. Folia Geobotanica 48: 23-38. https://doi.org/10.1007/s12224-012-9138-9

Onipchenko VG, Semenova GV and van der Maarel E (1998) Population strategies in severe environments: alpine plants in the northwestern Caucasus. Journal of Vegetation Science 9(1): 27-40. https://doi.org/10.2307/3237220

Petraglia A, Tomaselli M, Petit Bon M, et al. (2014) Responses of flowering phenology of snowbed plants to an experimentally imposed extreme advanced snowmelt. Plant Ecology 215: 759-768. https://doi.org/10.1007/s11258-014-0368-1

Richardson BA, Chaney L, Shaw NL and Still SM (2017) Will phenotypic plasticity affecting flowering phenology keep pace with climate change? Global Change Biology 23: 2499-2508. https://doi.org/10.1111/gcb.13532

Rixen C, Freppaz M, Stoeckli V, et al. (2008) Altered snow density and chemistry. Arctic and Alpine Research 40: 568575. https://doi.org/10.1657/1523-0430(07-044)

Schmid SF, Stöcklin J, Hamann E and Kesselring H (2017) High-elevation plants have reduced plasticity in flowering time in response to warming compared to low-elevation congeners. Basic and Applied Ecology 21. Elsevier GmbH: 112. https://doi.org/10.1016/j.baae.2017.05.003

Sedlacek J, Wheeler JA, Cortés AJ, et al. (2015) The response of the alpine dwarf shrub Salix herbacea to altered snowmelt timing: Lessons from a multi-site transplant experiment. PLoS ONE 10: 1-19.https://doi.org/10.1371/journal.pone.0122395

Steltzer H and Post E (2009) Seasons and life cycles. Science 324: 886-887. https://doi.org/10.1126/science.1171542

Totland $\varnothing$ and Alatalo JM (2002) Effects of temperature and date of snowmelt on growth, reproduction, and flowering phenology in the arctic/alpine herb, Ranunculus glacialis. Oecologia 133(2): 168-175. https://doi.org/10.1007/s00442-002-1028-z

Wang H, Liu G, Li Z, et al. (2016) Driving force and changing trends of vegetation phenology in the Loess Plateau of China from 2000 to 2010. Journal of Mountain Science 13: 844-856. https://doi.org/ 10.1007/s11629-015-3465-2

Wijk S (1986) Performance of Salix herbacea in an alpine snowbed gradient. The Journal of Ecology 675-684. https://doi.org/10.1007/BFo2347098

Wipf S, Stoeckli V and Bebi P (2009) Winter climate change in alpine tundra: plant responses to changes in snow depth and snowmelt timing. Climatic Change 94(1-2): 105-121. https://doi.org/10.1007/s10584-009-9546-x 